\title{
Língua, cultura e léxico: confluências entre Lexicografia e Filologia
}

\author{
Language, culture and lexicon: confluences between \\ Lexicography and Philology
}

\author{
Maria Helena de Paula* \\ Mayara Aparecida Ribeiro de Almeida** \\ Rayne de Mesquita Rezende***
}

\begin{abstract}
RESUMO: O presente estudo objetiva investigar as relações entre língua e cultura, especificamente no estado de Goiás. É no léxico, um dos subsistemas da língua, que melhor se identifica a conexão entre língua e cultura, porque cabe a ele o exercício de designar, através dos nomes, os referentes constituintes do sistema extralinguístico. No encalço dessa investigação, foi utilizado um corpus, elaborado a partir de duas ciências que têm como objeto de estudo a língua, em suas respectivas matizes, a Lexicografia e a Filologia. Para tanto, listaram-se algumas unidades lexicais do campo lexical da escravidão em documentos manuscritos eclesiásticos e cartoriais do século XIX da Cidade de Catalão-GO, cotejadas em quatro acervos lexicográficos: o "Dicionário do Brasil Central" (ORTÊNCIO, 2009) em sua versão eletrônica, o vocabulário registrado por Amaral (1976), ambos classificados como regionalistas; o dicionário de Moraes Silva (1922), contemporâneo ao registro dos documentos; e o de Houaiss e Villar (2009), na versão eletrônica. O que se verificou é que os signos são capazes de carregar, conservar ou modificar seus sentidos de acordo com as concepções ideológicas e culturais vigentes na sociedade no momento em que são registrados. O suporte teórico para o estudo consiste em clássicos da Lexicografia e da Filologia, como Biderman (1984, 2001), Spina (1977), Megale e Toledo Neto (2005), dentre outros.
\end{abstract}

PALAVRAS-CHAVE: Lexias. Cultura. Escravidão. Goiás.

ABSTRACT: The present study aims to investigate the relation between language and culture, specifically in the state of Goiás. The lexicon is one of the subsystems the language and it identifies better the connection between language and culture, because his function is to designate through the names the relative that constitute extralinguistic system. In pursuit this research, was used a corpus, it was drawn from two sciences: the lexicography and philology, that it has purpose of study the language in their

\footnotetext{
* Universidade Federal de Goiás - UFG. Regional Catalão. Laboratório de Estudos do Léxico, Filologia e Sociolinguística (LALEFIL). Bolsista FAPEG (processo no 201510267000990) Contato: mhp.ufgcatalao@gmail.com.

** Universidade Federal de Goiás - UFG. Regional Catalão. Laboratório de Estudos do Léxico, Filologia e Sociolinguística (LALEFIL). Mestranda em Estudos da Linguagem na UFG, com bolsa da CAPES. Contato: may_aparecida20@hotmail.com

${ }^{* * *}$ Universidade Estadual Paulista - UNESP. Campus Araraquara. Doutoranda em Linguística e Língua Portuguesa, com bolsa do CNPq. Contato: rayne.letrasufg@gmail.com
} 
differents hues. Therefore, listed some lexical units of the lexical field of slavery in handwritten documents and ecclesiastical notary XIX century in Catalão-GO, that they were compared with four lexicographical collection: the "Dicionário do Brasil Central subsídios à Filologia" (ORTÊNCIO, 2009) in the electronics version, the vocabulary recorded by Amaral (1976), both classified as regionalists, the dictionary Moraes Silva (1922), that is contemporary in relation to recording of documents, and the Houaiss (2009), in the electronic version. What was found is that the signs are able to load, save or modify your senses according to ideological conceptions and cultural force in society at the time are recorded. The theoretical support for the study consisted of classical Philology and Lexicography, as Biderman (1984, 2001), Spina (1977), Megale and Toledo Neto (2005), among others.

KEYWORDS: Lexias. Culture. Slavery. Goiás

\section{Palavras iniciais}

O presente artigo objetiva fazer uma investigação das relações entre língua e cultura, tendo como foco o léxico. Para a melhor compreensão da proposição, é imprescindível considerar as inter-relações entre língua, cultura e léxico; posteriormente, apresenta-se a metodologia, ancorada em duas ciências da linguagem, a Lexicografia e a Filologia, cada qual com enfoques diferenciados, mas que - neste estudo -, concedem expedientes fiáveis para a seleção do corpus de análise.

A matéria linguística deste estudo consiste de três lexias, recorrentes em documentos manuscritos cartoriais e eclesiásticos, em suas versões fac-similar e semidiplomática e que fazem parte do acervo digital do Laboratório de Estudos do Léxico, Filologia e Sociolinguística (LALEFIL), da Unidade Acadêmica Especial de Letras e Linguística da Universidade Federal de Goiás - Regional Catalão. Do primeiro códice, o Livro de Notas do 20 Tabelliaõ - Carlos Antônio de Andrade, exarado no ano de 1861 na cidade do Catalão-GO, foram utilizados três fólios: o 53 recto, o 57 verso e o 58 recto. Do segundo códice, fez-se uso do Livro de Registro de Batizados da Paróquia Nossa Senhora Mãe de Deus (maio de 1837 a setembro de 1838).

Após o levantamento das lexias em seu contexto de uso nos dois corpora, estas foram cotejadas com quatro instrumentos lexicográficos, a saber: um 
vocabulário contido na obra O Dialeto Caipira ${ }^{1}$, de Amadeu Amaral (1976); o Dicionário do Brasil Central, de Ortêncio (2009); o Diccionario da Língua Portugueza ${ }^{2}$ de Antonio Morais Silva (1922) e o dicionário Houaiss e Villar (2009), na versão eletrônica. A escolha por estas obras para o cotejo de sentidos se justifica por serem as duas primeiras de cunho regionalista que, em certa medida, deveriam recobrir os usos ditos específicos da região em que foram escritos os documentos em tela; a terceira por ser coetânea aos documentos e a última por representar indícios de manutenção de sentidos atualmente conhecidos e por ser, ainda, uma obra que preza por apresentar datações em muitos verbetes.

Cabe, ainda, justificar a escolha dessa abordagem metodológica por entender que o estudo da língua através da perspectiva lexicográfica e filológica possibilita a análise da sua história, além de apontar indícios de sua evolução ou da manutenção dos significados ou sentidos de uma unidade lexical. As duas ciências têm em comum a capacidade de apontar dados e análises de signos e seus significados por terem como objeto a matéria linguística empírica em uso (a Filologia) e as relações de sentido inscritas nos atos de nomeação, registradas nos verbetes (Lexicografia).

O corpus em que se estrutura a presente investigação foi constituído de documentos manuscritos que encaminham a conhecer o momento históricocultural em que foram exarados na cidade de Catalão, província de Goiás em meados do século XIX; por isso, faz-se necessário abordar em linhas gerais a história local, com ênfase nas práticas do sistema escravocrata em vigor, posto que as lexias selecionadas nos manuscritos são parte integrante do campo lexical da escravidão.

\section{Aspectos relevantes do movimento escravocrata em Goiás}

Goiás, "descoberto" por Bartolomeu Bueno da Silva, o Anhanguera, no ano de 1725, após três anos de incessante busca por minas de ouro, pelos territórios brasileiros, tem sua história marcada pelo sistema econômico de servidão, porque

\footnotetext{
${ }^{1}$ A primeira edição data de 1922.

${ }^{2}$ A primeira edição data de 1813 .
} 
o negro escravo foi inserido neste cenário como a mão de obra que deveria trabalhar com afinco em várias áreas, como a mineração e, mais tarde, a lavoura, além dos serviços domésticos, para garantir a riqueza de seus donos.

De acordo com Palacín e Moraes (1989), o Anhanguera tinha fortes indícios de que no território goiano teriam muitos minérios preciosos, uma vez que essa região situa-se entre os estados de Minas Gerais e Mato Grosso, onde foram encontradas muitas minas de ouro. Assim, acreditando que este território detinha riquezas imensuráveis, Bartolomeu pediu permissão ao rei para organizar uma bandeira com destino às terras goianas; com a permissão concedida e mediante o cumprimento das regras estabelecidas pela Coroa, inicia-se a empreitada.

O descobrimento desse território deu início ao processo de seu povoamento, trazendo consigo inúmeros escravos africanos e seus descendentes os quais, sob o regime escravocrata vigente, exauriram suas forças em trabalhos braçais nas jazidas minerais. Segundo Palacín e Moraes (1989), Ihes custavam uma vida sofrida e curta, pois, devido às más condições de trabalho e ao longo período dessa jornada e sem alimentação adequada, esses cativos suportavam em média sete anos de servidão.

Vale ressaltar que esse povoamento ocorreu desordenadamente, levando em consideração que eram construídos arraiais naquelas regiões onde se descobriam rios auríferos. Quando essa riqueza era explorada por completo o arraial era abandonado e buscavam-se, então, novos locais para recomeçar outras atividades extrativistas.

No tocante aos escravos que passaram por Catalão (ou aí permaneceram), salienta-se que estes tiveram suas vidas consumidas na atividade agrícola, uma vez que a economia desta região sempre foi de base rural, em especial servindo à provisão de quem entrava na Capitania, depois Província de Goiás, ou dela saía, na busca insaciável por pedras preciosas. Sustenta-se esta tese, neste estudo, mediante o que registraram os documentos manuscritos encontrados nessa cidade, que trazem registros das ocupações desempenhadas pelos cativos.

Quanto à constituição linguística do estado de Goiás, defende-se aqui que seus pilares de sustentação partiram das línguas indígenas, especialmente o tupi, 
do português falado pelo colonizador bandeirante e da absorção das influências que vieram junto com os negros africanos de variadas etnias.

É fato que a língua portuguesa sagrou-se como língua oficial do Brasil, com as perceptíveis marcas deixadas pelas línguas indígenas e africanas no vocabulário dos brasileiros, mas também pela herança portuguesa do século XVI. Na seção seguinte, serão abordadas as relações entre língua e cultura como arcabouço fundamental para organização das sociedades humanas.

\title{
Reflexões sobre língua e cultura
}

A língua é um construto histórico-social, coletivo e presente na memória dos agentes de uma comunidade linguística qualquer e tem como função primeira a comunicação entre esses agentes.

Então, se a função primordial da língua consiste em tornar comum e compreensível o que está presente no cotidiano dos indivíduos de uma sociedade, seja material ou imaterial, é necessário que as designações e as formas como as serão utilizadas sejam elaboradas a partir de um consenso entre os membros de um grupo. Segundo Paula (2007, p. 92),

\begin{abstract}
A complexa rede de significados que sustenta o caráter de semiótica social da língua tem organização própria, porém não autônoma. A cultura, esse tecido dinâmico e inconsútil de significados, se faz e refaz graças às suas formas lingüísticas de expressão. É na sua manifestação lingüística que a materialidade cultural se constitui, também, um sistema de linguagem. Hábitos, crenças, saberes se repassam como cultura pelo ato não raro de repetição por outros, mas sua consciência simbólica de significação da coletividade se assegura e se reforça graças à configuração lingüística.
\end{abstract}

A cultura, vista como "todo este complexo que inclui conhecimentos, crenças, arte, moral, leis, costumes, ou qualquer outro hábito ou capacidade adquiridos pelo homem como membro de uma sociedade", é um conceito de dimensão etnográfica mais amplo, elaborado por Edward Tylor, em 1871 (LARAIA, 2001, p. 54). A oposição entre aprendizado e aquisição inata, transmitida biologicamente, é o ponto de partida para a distinção entre os fatos orgânicos, comuns a todos os seres vivos e os etnográficos. 
Neste sentido, Leslie White (apud LARAIA, 2001, p. 55), antropólogo norte-americano, atenta para a importância da capacidade humana de decodificação do mundo em símbolos. Para ele, todo construto cultural depende dos símbolos e é essa faculdade de transposição/representação, de interpretação de fatos comportamentos e objetos através de símbolos que distingue o homem das demais espécies de seres vivos. Sob esse enfoque, a cultura integra a ordem dos fenômenos superorgânicos.

A simbolização aludida por White abrange uma extensão incomensurável de formas de expressão, dentre as quais se situa a linguagem verbal, sobre a qual nos detemos a discorrer em consonância com o objeto e o objetivo deste trabalho. Esta, por sua vez, se mantém viva e configura um sistema dinâmico e abstrato porque é necessária para designar os fatos materiais e imateriais externos ao campo da língua.

Nesta ótica, a língua funciona como um veículo que transporta e espalha essas práticas culturais, embora não se modifique com a mesma intensidade que elas, pois a língua, enquanto sistema, possui uma estrutura interna regida por princípios de linearidade e arbitrariedade. Dizendo de outro modo, para que haja uma mudança na língua, é preciso que essa alteração não interfira na estrutura que permite o entendimento, a comunicação entre seus usuários, e que seja aceita por eles no cotidiano dos usos linguísticos.

Assim, a língua configura-se como um diassistema que tem por sustentáculo três subsistemas menores; o discurso, a gramática e o léxico. 0 discurso corresponde aos sentidos vários conferidos na materialidade da linguagem em uso; a gramática corresponde ao conjunto de normas que regem as combinações possíveis na estrutura interna da língua; o léxico constitui um inventário aberto das unidades significativas que denominam os referentes abstratos e concretos do sistema extralinguístico.

O processo de nomeação que dá origem ao léxico da língua surge a partir do momento em que um nome é socialmente aceito para tal. Destarte, pode-se dizer que este processo de nomear abarca a fração cultural da língua, uma vez que ao se designar um objeto através do nome, está-se autenticando sua 
existência nesse mesmo meio social. Assim, o léxico é dos subsistemas da língua o que melhor reflete os traços culturais de uma comunidade linguística. Nas palavras de Vilela (1994, p. 6),

O léxico é a parte da língua que primeiramente configura a atividade extralinguística e que arquiva o saber linguístico duma comunidade. Avanços e recuos civilizacionais, descobertas e inventos, encontros entre povos e culturas, mitos, crenças, afinal quase tudo, antes de passar para a língua e para a cultura dos povos, tem um nome e esse nome faz parte do léxico. O léxico é o repositório do saber linguístico e é ainda a janela através da qual um povo vê o mundo. Um saber partilhado que apenas existe na consciência dos falantes duma comunidade.

Assim, o léxico das línguas naturais engloba todo o conhecimento que todos os falantes de uma língua natural têm, rotulado sob a forma de nomes que podem ser chamados também de unidades ou palavras lexicais. $\mathrm{O}$ nome, além de designar, traz consigo uma história, pois sempre existe uma motivação que de certa forma justifica a opção de uma comunidade linguística por determinado nome. Este pode remeter ainda a diversas realidades, pois um nome/signo pode ter uma significação geral e uma específica, a depender de diversos fatores, como o momento histórico ou o contexto social em que for utilizado, constituindo um vocabulário correspondente a uma situação peculiar.

Associam-se, então, os semas possíveis de uma unidade lexical ao conjunto significativo disponível no paradigma léxico e que abrange genericamente todos os usos possíveis de uma unidade léxica. Por seu turno, o sentido configura um uso mais restrito e é aqui associado à lexia. Por ser generalizante e representar o eixo paradigmático, o significado está para a língua e para o léxico e, em contraparte, por dizer respeito ao uso, ser mais específico, o sentido está para o vocabulário e se apresenta nas lexias.

Em termos saussurianos, o léxico está para o paradigma e para a língua, porque representa o arcabouço conceptual geral, as combinatórias semânticas possíveis como intentam registrar os produtos lexicográficos, tais que dicionários e glossários. O vocabulário, por outro lado, está para o sintagma e para o sentido por se encontrar nos usos contextualizados e concretos. Assim, o vocabulário é 
uma atualização das unidades lexicais possíveis e disponíveis no léxico geral, que se efetivam nas situações de comunicação em que são plenamente utilizadas, passando do abstrato e possível (léxico / unidade lexical) para o concreto e efetivamente em uso (vocabulário/lexia).

Por estas possibilidades vastas de significação e usos efetivos, configurando-se em múltiplos e diversos arranjos na estrutura da língua, o léxico é o subsistema mais aberto e dinâmico, podendo ser estudado sob várias perspectivas, nas ciências (ou disciplinas da linguagem) que o tomam como objeto de estudo e o consideram capaz de permitir a comunicação e o registro das descobertas humanas. Entretanto, no estudo em questão, tomam-se apenas as ciências Lexicografia e a Filologia: a primeira tem como objeto de estudo o léxico em sua essência, legitimado pelo uso geral sob a forma de verbetes; a segunda é capaz de constituir corpus fiável e fidedigno para o estudo de lexias. No caso deste estudo, a metodologia emprestada da Filologia assegura ao material de estudo um estado de língua como usada nos anos oitocentos em Goiás e, por isso, importa à proposição inicial, pois garante que as lexias, nos contextos apresentados, tenham tido o uso como se manuscreveram nos registros documentais.

Na seção que segue, serão discutidas em linhas gerais as funções e os pontos de contato entre as duas ciências que balizam o estudo ora apresentado, focando em suas contribuições para as pesquisas linguísticas.

\section{Lexicografia e Filologia: contribuições para os estudos linguísticos}

Antes de avançar sobre os objetivos e a metodologia da Lexicografia, fazse necessário reportar a outra ciência que, embora posterior a esta, lhe fornece os critérios necessários para a formulação dos pressupostos teóricos com as quais opera a Lexicografia. Esta ciência é a Lexicologia.

Basicamente, a Lexicologia define-se como "ciência que tem como objetos básicos de estudo e análise a palavra, a categorização lexical e a estruturação do léxico." (BIDERMAN, 2001, p. 16). Cabe à Lexicologia investigar a organização interna do léxico, bem como o estudo e a classificação da palavra e suas 
categorizações léxico-gramaticais, além da distinção entre os conceitos com os quais ela atua e que servem de base também para a Lexicografia como a complexa conceituação de palavra, a questão da não existência de sinônimos que tenham equivalência semântica total, entre outras atribuições.

A Lexicografia consiste na ciência que se ocupa da produção dos dicionários e dos demais produtos lexicográficos. Estes têm como objetivo registrar as unidades lexicais da língua e seus significados de forma sistematizada. De acordo Krieger (2006, p. 165),

[...] o registro sistematizado do léxico confere ao dicionário o estatuto de instância de legitimação das palavras de uma língua. Esta legitimação é também uma das razões pelas quais o dicionário é considerado também como paradigma linguístico dos usos e sentidos das palavras e expressões de um idioma. Nessa medida, a obra dicionarística monolíngüe cumpre o papel de código normativo de um sistema linguístico, funcionando como um dos instrumentos reguladores das regras do bem-dizer das comunidades linguísticas. Por tudo isto, o dicionário goza de uma autoridade que não é menor nas sociedades de cultura.

Depreende-se, então, que o dicionário, além de uma grande lista de palavras acompanhada de seus significados e sua grafia correta, funciona também como um veículo das ideologias que regem a sociedade e que nele vêm registradas, às vezes mais explicitamente, às vezes de forma mais subliminar. De acordo com Borba (2003), o dicionário, que também configura um tipo de texto, não está livre de propagar, em suas entrelinhas, certos ideais. E assegura ainda Borba (2003, p. 308-309) que:

Um dicionário de língua, como produto cultural e instrumento pedagógico, resulta de um olhar sobre a estrutura e o funcionamento do sistema linguístico num determinado momento da vida de uma comunidade. Por isso, é organizado a partir de uma ideologia. Ela pode estar explícita na introdução ou pode ser inferida da seleção dos verbetes, da rotulação de entradas, do sistema definitório etc.

O dicionário geral encabeça a lista dos produtos mais conhecidos do labor lexicográfico, embora não seja o único dos resultados dessa ciência. Há, ainda, como produtos lexicográficos, os vocabulários, os glossários, as enciclopédias, os dicionários de especialidades e os terminológicos. 
No presente trabalho, serão abordados os três tipos de instrumentos lexicográficos utilizados para a composição do corpus. um vocabulário, um dicionário de regionalismos e dois dicionários gerais da língua portuguesa, um deles é contemporâneo ao período em que foram escritas as certidões de batismo dos escravos e documentos cartoriais apresentadas nos manuscritos e o outro, correspondente aos dias atuais, como já justificado anteriormente.

O vocabulário, o dicionário de regionalismos e o dicionário geral têm em comum algumas características no que diz respeito à sua nomenclatura, ou seja, à maneira como as palavras estão dispostas: em ordem alfabética, seguidas de uma definição, que é a descrição do lema (o que é, para que serve, quando e como pode ser empregado).

Conforme Coelho (2008, p. 21), a característica distintiva entre um dicionário e um vocabulário é o fato de este ser constituído de um conjunto de palavras cujos usos são restritos a um determinado campo, ou obra, e as definições trazidas são mais breves e raramente contém exemplos ou abonações.

O dicionário de regionalismos, comparativamente ao geral, intenta registrar apenas uma parcela dos usos e significados do léxico da língua, correspondente à variação diatópica qualquer e, por isso, é classificado como um dicionário de especialidades. São classificados como de especialidades os dicionários que priorizam por registrar uma parte análoga a um determinado tema ou assunto.

Já o dicionário geral da língua tem como propósito registrar uma grande quantidade de unidades lexicais básicas, além de algumas cujas ocorrências não são tão frequentes, sendo destinado ao público geral usuário da língua. Convém salientar que, embora haja um grande esforço por parte da lexicografia em inventariar o maior número de unidades léxicas possível em um dicionário geral, sabe-se que isto não é possível por conta do caráter diligente e abarcador da língua.

Por sua vez, a Filologia tem como objeto de estudo o texto, de modo específico e, preferencialmente, o texto escrito antigo, o qual é um instrumento 
que permite conhecer aspectos da história e cultura de um povo, das pessoas que estão sendo representadas no estado de língua estudado.

Assim, a função primordial do filólogo ao lidar com estes textos é, segundo Spina (1977, p. 75),

A explicação do texto, tornando-o inteligível em toda a sua extensão e em todos os seus pormenores, apela evidentemente para disciplinas auxiliares a (literatura, a métrica, a mitologia, a história, a gramática, a geografia, a arqueologia, etc.).

No que diz respeito à interdisciplinaridade dos estudos filológicos, citamse a Lexicologia e a Lexicografia como ciências que Ihes são auxiliares, tendo em vista que para o filólogo alcançar uma explicação fiel do texto certamente recorrerá, dentre outros, ao componente lexical para explicar lexias desconhecidas e/ou portadoras de outros significados. Esta prática é bastante comum na leitura e interpretação filológicas, visto que lida com escritos antigos que geralmente possuem uma variação lexical notável, o que pode comprometer a interpretação do texto caso o filólogo não se atente a particularidades diacronicamente identificadas.

Por outro lado, a Filologia serve à Lexicologia e à Lexicografia, oferecendoIhes fontes fidedignas para seus estudos, como é o caso do corpus utilizado neste estudo, que nos põem em contato com o registro escrito da língua vigente no século XIX, remontando a um campo lexical que se refere à escravidão, subtema tratado mais adiante.

A respeito dos pontos de intersecção destas áreas de estudo, Xavier (2011, p. 4) defende que:

[...] a edição conservadora de textos antigos traz a lume a norma lexical corrente em determinada época, que pode embasar pesquisas sobre a renovação do léxico, arcaísmos, dentre outras. Similarmente, os textos editados filologicamente também fornecem dados de relevância para a lexicografia, porquanto permite resgatar usos e acepções remotas dos lexemas, assim como informações sobre a datação destas.

Diante disso, acredita-se que este trabalho se faz de muita valia aos estudos da linguagem, sobretudo os de viés interdisciplinar, por realizar um estudo lexical unindo esses três campos do saber que, juntos, possibilitam chegar 
a uma compreensão maior da língua, neste caso, estudar a fundo as três lexias selecionadas.

Acredita-se também que a validade deste estudo se respalda não apenas em trabalhar com essas áreas, mas, sobretudo, pelo material utilizado, trazido à baila em contextos de uso nos idos do século XIX. Utilizou-se uma edição facsimilar semidiplomática, constante do acervo digital do LALEFIL- UFG/CAC, como retro mencionado. A edição fac-similar, segundo Spina (1977), reproduz mecanicamente, via fotografia e, fielmente, o documento, de modo que a intervenção do editor resume-se à escolha do melhor instrumento para tal como fotocopiadora, máquina digital ou aparelho de scanner para traduzir as características originais do documento. A fidedignidade reproduz caracteres tais que a cor, formato do papel, filigranas, especificidades paleográficas e codicológicas.

Por outro lado, a edição semidiplomática é uma lição conservadora que preserva o estado da língua estudada, possibilitando a sua utilização para outros estudos como os lexicais e, ao mesmo tempo, permite ao editor intervir em algumas lacunas presentes no texto original, para facilitar a compreensão por parte de seu leitor.

Dessas intervenções destacam-se o desenvolvimento de abreviaturas, marcando em itálico as letras que estejam omitidas no original; o encaminhamento para nota de rodapé de eventuais erros ou equívocos do escriba ou copista, registrando a sua correção; a intervenção do editor, feitas somente quando se fizeram de extrema necessidade, as quais devem vir entre colchetes, dentre outras. Vale ressaltar que a edição desses textos segue as "Normas para Transcrição de Documentos Manuscritos para a História do Português do Brasil" que se encontram publicadas em Megale e Toledo Neto (2005).

Para dar continuidade ao propósito deste estudo, segue-se uma análise lexical dos dados levantados durante a organização do presente corpus sob o enfoque do campo lexical da escravidão. Sobre os campos lexicais, Abbade (2011, p. 133, com grifos da autora) afirma: 
Os campos lexicais representam uma estrutura, um todo articulado, onde há uma relação de coordenação e hierarquia articuladas entre as palavras que são organizadas à maneira de um mosaico: 0 campo léxico. As palavras são organizadas em um campo com mútua dependência, adquirindo uma determinação conceitual a partir da estrutura do todo. O significado de cada palavra vai depender do significado de suas vizinhas conceituais. Elas só têm sentido como parte de um todo, pois só no campo terão significação. Assim, para entender a lexia individualmente é necessário observá-la no seu conjunto de campo, pois fora desse conjunto não pode existir uma significação, uma vez que a mesma só existe nesse conjunto e em sua razão.

Assim, pode-se conceber o campo lexical como uma rede de associações em que as unidades lexicais estão organizadas segundo uma relação de interdependência, pois só têm um determinado sentido de acordo com o conjunto de circunstâncias que acompanham um fato ou situação de significação.

Para a organização de um campo lexical qualquer, é preciso, antes, uma análise de cunho onomasiológico partindo do sentido que um grupo de unidades lexicais obtém consoante à situação extralinguística que designam. Conforme os pressupostos teóricos de Coseriu, citado por Abbade (2009, p. 42),

Dessa forma, Eugênio Coseriu, ao estudar a estruturação dos campos lexicais, propõe sempre um estudo diacrônico e estrutural do léxico onde se possa investigar o funcionamento de uma língua, partindo-se da significação estrutural para a designação, ou seja, a língua é descrita como estruturação de conteúdos.

De uma maneira simplificada, o campo lexical se trata de um conjunto de lexias cujos significados e sentidos estão relacionados por aspectos de um contexto ou situação; no estudo em questão, o contexto é a escravidão na cidade de Catalão em meados do século XIX.

A tabela a seguir traz três lexias recorrentes na edição dos registros de batismo, hipoteca e escritura de compra e venda dos escravos nos manuscritos a que se reporta a análise, acompanhada de abonações, alguns trechos das edições semidiplomáticas destes documentos. 
Quadro 1- Campos lexicais da escravidão

\begin{tabular}{|c|c|}
\hline $\begin{array}{l}\text { Unidades } \\
\text { Lexicais }\end{array}$ & Abonações $^{34}$ \\
\hline \multirow[t]{2}{*}{ Banguella } & $\begin{array}{l}\text { Aos trinta de Março de mil oito centos etrinta eoito } \mid<\text { Roza }>\text { nesta Villa do } \\
\text { Catalaõ, compareceo em Caza de } \mid<\text { Banguela }>\text { minha Rezidencia Francisco } \\
\text { Ignacio Bueno |com úma sua escrava de nascaõ Banguella } \mid<\text { Escrava }>\text { para } \\
\text { ser Baptizada, e morador na Fazenda |da Prapettinga, eno mesmo dia Supra } \\
\text { dito Ba- I ptizei Solemnemente epus os Santos Olleos a dita | escrava de nome } \\
\text { Roza, em a Matris desta Villa (24r) }\end{array}$ \\
\hline & $\begin{array}{l}\text { compareceo em Caza de minha rezidencia Joaõ Rodriguez | de Faria com hum } \\
\text { menino, criolo nascido a20 de Março proximopassado |pelas } 8 \text { horas da noite } \\
\text { na Fazenda do Guarteis, fillho legetimo de |Joaquim, Angolla, e Vitoria } \\
\text { Banguella, ambos escravos do dito|Joaõ Rodriguez de Faria, e sua mulher } \\
\text { Francisca Pedroza de Lima, moradores na | dita Fazenda onde vevem de } \\
\text { Lavoura (36v) }\end{array}$ \\
\hline \multirow[t]{2}{*}{ Cabra } & $\begin{array}{l}\text { me foi apresentado úm me-|nino, criolo, nascido a } 30 \text { de Agosto, proximopass } \\
\text { horas da noite, I filho natural de Antonia cabra escrava de Manoel Gonsalves | } \\
\text { Pacheco, morador na Fazenda denominada Ranxaria (12r) }\end{array}$ \\
\hline & $\begin{array}{l}\text { e no mesmo dia supra dito, Baptizei solemnemente | epus os Santos Olleos ao } \\
\text { dito menino de nome Francisco, Cabra | filho natural de Anna Cabra escrava } \\
\text { de Joze Pinheiro de | alvarenga, morador na dita Fazenda, onde veve de } \\
\text { Lavoura (15v) }\end{array}$ \\
\hline \multirow[t]{2}{*}{ Senhor(es) } & $\begin{array}{l}\text { Digo eu abaixo assig- | na do Vicente Pereira da Lus, eminha mulher | Anna de } \\
\text { Jesus que entre os mais seres que | somos Senhores epossui dores, [...] } \\
\text { Administraçaõ é livre assim um | Escravo denome Misael pardo ao qual como } \\
\text { I demos emvirtude detomasua liberdade | sendo este beneficio feito muito de } \\
\text { I nossas livres iespontanias vontades, esem | constrangimento depessoa } \\
\text { alguma (53r). }\end{array}$ \\
\hline & $\begin{array}{l}\text { na | presença das quaes pelo dito Sabino Diasde| Car valho foi dito que, } \\
\text { Ellehe Senhor epos- }|| 58 \mathrm{r}|| \text { Epossuidor dehum escravo crioulo denome Jus | } \\
\text { tino, dei dade devinte annos mais ou | menos, o qual elle desua livrevontade } \\
\text { | Hypoteca, ehypotecado tem emmão epo | der de Pedro Martins Monteiro pela } \\
\text { qu | antia de quatro centos etrinta mil | reis. (57v e 58r) }\end{array}$ \\
\hline
\end{tabular}

\footnotetext{
3 É comum em algumas abreviaturas certos grafemas aparecerem sobrescritos, por isso faz-se necessário informar, mediante nota explicativa, em que palavras nestas abonações ocorreu esse processo e quais os termos que foram sobrescritos. Na primeira abonação da lexia <Banguella $>$ nas palavras $\langle$ Março $\rangle,\langle$ Francisco $\rangle$ e $<$ Solemnemente $\rangle$ os grafemas $\langle c ̧\rangle$ e $\langle 0\rangle,\langle$ c $\rangle$ e $\langle 0\rangle$, $<\mathrm{t}>\mathrm{e}<\mathrm{e}>$ aparecem sobrescritos, respectivamente. Já na segunda abonação dessa lexia, nas palavras <Rodriguez>, <mulher > e <Francisca > aparecem sobrescritos, sucessivamente, o sinal de nasalização $(\sim)$ indicando que houve supressão de uma ou mais letras, os grafemas <e> e $<$ r $>$ e os grafemas $\langle\mathrm{c}\rangle$ e $\langle\mathrm{a}\rangle$. Na lexia $<$ cabra $\rangle$ verifica-se esse processo somente na segunda abonação, em que os grafemas $\langle\mathrm{t}\rangle$ e $\langle\mathrm{e}\rangle,\langle\mathrm{c}\rangle$ e $\langle 0\rangle$ e $\langle\mathrm{a}\rangle$ aparecem sobrescritos, consecutivamente, nas palavras: <solemnemente $>$, $<$ Francisco $>$ e $<$ dita $>$. E na última lexia desse quadro, $<$ Senhor $>$, encontra-se apenas uma abreviatura, em que na palavra $<$ minha $>0$ grafema <a> aparece sobrescrito.

${ }_{4}^{4}$ É importante sublinhar que nessas abonações apresentamos trechos da edição semidiplomática dos manuscritos, de acordo com as "Normas para transcrição de documentos manuscritos" dispostas em Megale e Toledo Neto (2005), as quais orientam que se mantenha a ortografia e fronteira de palavras presentes nos documentos originais.
} 
Feito o levantamento dos vocábulos de maior recorrência que compõem os documentos editados, passa-se para a próxima etapa da investigação, o cotejo dessas lexias com o vocabulário e os três dicionários, para verificar, primeiramente, se as lexias estavam dicionarizadas e, em seguida, quais foram os significados e sentidos relacionados à escravidão que se mantiveram ou se alteraram com o passar do tempo.

Diante do exposto, optou-se por colocar no quadro seguinte apenas as acepções relacionadas ao tema, uma vez que o foco investigativo é o campo lexical relativo à escravidão não parece ser necessário apontar aqui as demais acepções que as lexias possam ter adquirido ou possuam.

Assim, a composição da tabela abaixo consiste na lexia/unidade lexical retirada do manuscrito, conservando a grafia com a qual se apresentava, seguida das acepções encontradas em cada um dos instrumentos lexicográficos da qual se lança mão para a execução da parte analítica deste estudo. As palavras entre colchetes equivalem à forma como estão grafadas no vocabulário de Amaral (1976), em Ortêncio (2009), Moraes Silva (1922) e Houaiss e Villar (2009).

O que alvitrou, na presente análise, foi identificar os traços sêmicos adquiridos pelas lexias na situação da escravidão, bem como observar se houve variação diatópica (que se verificaria, hipoteticamente, nos dois expedientes lexicográficos regionais) no nível semântico dessas unidades léxicas.

No campo lexical da escravidão, constatou-se que as lexias banguela e cabra assumem sentido atinente a questões de etnia e cor, respectivamente. Quanto à lexia senhor, observa-se que tem o sentido de alguém que tem certa autoridade, poder de decisão sobre algo, o que tem posse sobre o escravo. 
Quadro 2 - Cotejo de banguela, cabra e senhor

\begin{tabular}{|c|c|c|c|c|}
\hline $\begin{array}{c}\text { Unidades } \\
\text { lexicais }\end{array}$ & Amaral (1920) & Ortêncio (2009) & $\begin{array}{c}\text { Silva } \\
(1813)\end{array}$ & Houaiss (2009) \\
\hline Banguella & $\begin{array}{l}\text { [Banguéla] q. - que } \\
\text { tem falta dos dentes } \\
\text { da frente. (p. 95). }\end{array}$ & $\begin{array}{l}\text { [Banguela] } 1 \\
\text { Pessoa } \\
\text { desdentada. } 2 \\
\text { Ponto morto[....]. }\end{array}$ & $\begin{array}{l}\text { Unidade } \\
\text { lexical não } \\
\text { registrada }\end{array}$ & $\begin{array}{l}\text { [Banguela] adj. De } \\
\text { dois gên. subst. de } \\
\text { dois gên. Reg. } \\
\text { Brasil. 1. m. q. } \\
\text { benguella. 2. Que } \\
\text { ou quem se } \\
\text { ressente da falta } \\
\text { de um ou mais } \\
\text { dentes na parte } \\
\text { frontal de uma ou } \\
\text { ambas arcadas. }\end{array}$ \\
\hline Cabra & $\begin{array}{l}\text { Cabra, s.m. - mulato } \\
\text { moço, ou criança ( } \text {. } \\
\text { 104). }\end{array}$ & $\begin{array}{l}\text { Cabra - } 1 \\
\text { Jagunço [...] } 2 \\
\text { cabra-cega } \\
\text { Folguedo, em que } \\
\text { a cabra-cega é } \\
\text { uma participante } \\
\text { de olhos } \\
\text { vendados: }\end{array}$ & $\begin{array}{l}\text { Cabra, }[\ldots] \\
\text { §O filho, ou } \\
\text { filha de pai } \\
\text { mulato e mãe } \\
\text { preta, ou às } \\
\text { avessas }[. . . .]\end{array}$ & $\begin{array}{l}\text { Cabra - Reg. Brasil } \\
\text { [...] } 9 \text { mestiço } \\
\text { indefinido, de } \\
\text { negro, índio ou } \\
\text { branco, de pele } \\
\text { morena clara [...]. }\end{array}$ \\
\hline Senhor & $\begin{array}{l}\text { [Sinhôr] Sinhô, } \\
\text { sinhô, siôr, siô, } \\
\text { formas enclíticas de } \\
\text { senhor. [...] - } \\
\text { Adendo: sinhô, a } \\
\text { parte o que ficou } \\
\text { indicado, aparece em } \\
\text { próclise nas fórmulas } \\
\text { sinhô-moço e sinhô- } \\
\text { véio. É caso isolado, } \\
\text { devido já a outro } \\
\text { gênero de influência. } \\
\text { Essas fórmulas, tais } \\
\text { como se acham } \\
\text { grafadas, se devem } \\
\text { aos antigos escravos } \\
\text { negros (cuja fonética } \\
\text { especial, como já } \\
\text { assinalamos em } \\
\text { outro lugar, diferia, } \\
\text { em mais de um } \\
\text { ponto da fonética } \\
\text { popular dominante, } \\
\text { ou caipira) e forma } \\
\text { adotadas geralmente } \\
\text { para designar os } \\
\text { senhores em relação } \\
\text { aos seus cativos [...] } \\
\text { (p.180). }\end{array}$ & $\begin{array}{l}1 \text { Tratamento } \\
\text { respeitoso } \\
\text { dispensado aos } \\
\text { homens [...] } 3 \\
\text { Termo que, usado } \\
\text { antes de nomes } \\
\text { comuns, designa } \\
\text { que se trata de } \\
\text { algo importante, } \\
\text { respeitável, } \\
\text { excepcional ou de } \\
\text { excelente } \\
\text { qualidade }[. . . .]\end{array}$ & $\begin{array}{l}\text { Senhor, s.m. } \\
\text { o que tem } \\
\text { domínio de } \\
\text { algum } \\
\text { escravo ou } \\
\text { coisa;§senho } \\
\text { r útil, o que } \\
\text { tem domínio } \\
\text { útil; e não o } \\
\text { direito. [...]. } \\
\text { § É senhor } \\
\text { de si, de } \\
\text { suas ações, o } \\
\text { homem livre, } \\
\text { que não } \\
\text { depende de } \\
\text { outrem. [.... } \\
\text { § Senhor de } \\
\text { si; é quem } \\
\text { em perfeito } \\
\text { juízo, sem } \\
\text { perturbação, } \\
\text { sem paixão. } \\
\text { [....] § } \\
\text { Senhor do } \\
\text { campo; o } \\
\text { que } \\
\text { afugentou } \\
\text { delle o } \\
\text { inimigo. } \\
\text { [....]. }\end{array}$ & $\begin{array}{l}\text { Senhor s.m. } 1 . \\
\text { proprietário de } \\
\text { feudo. } 2 \text {. aquele } \\
\text { que possui algo; } \\
\text { dono, proprietário. } \\
\text { 3. dono da casa; } \\
\text { patrão, amo. } 4 . \\
\text { pessoa que exerce } \\
\text { poder, dominação, } \\
\text { influência. } 5 . \\
\text { aquele que tem } \\
\text { pleno domínio } \\
\text { sobre si, sobre uma } \\
\text { coisa, sobre uma } \\
\text { situação [...]. }\end{array}$ \\
\hline
\end{tabular}

Fonte: Adaptado: Amaral (1976), Ortencio (2009), Moraes Silva (1922), Houaiss e Villar (2009) 


\section{Análise das lexias}

Banguella [Banguela] - Exceto em Morais Silva (1922) - aparece nas outras obras de cotejo tendo como significado principal o indivíduo que se ressente da falta de um ou mais dentes. Outro significado também atribuído a esta lexia, e constante apenas em Houaiss e Villar (2009), é banguela como uma variante de benguela que, segundo esta obra, designa o povo ou indivíduo que habita a região de Benguela, província da Angola.

Em cotejo com o sentido atribuído a Banguella em seu contexto de uso, conforme pode ser observado na tabela 1 , nota-se que ela indica a nação das escravas Roza (fólio 24r) e Vitoria (fólio 36v), o que nos mostra que se trata realmente de uma variante de benguela. No entanto, o outro significado presente nos dicionários (pessoa desdentada) não pode ser descartado, isso porque o povo de Benguela tinha o costume de limar os dentes incisivos.

Acredita-se, deste modo, que com o tempo o termo banguela passou a designar mais do que a origem do indivíduo, mas também uma característica física sua, mostrando a dinâmica do léxico de uma língua, a todo o momento não só criando novas palavras como também atribuindo novos sentidos àquelas que já existem, de acordo com a necessidade de seus falantes.

Outro fato digno de nota é que em Houaiss e Villar (2009) consta que o primeiro registro desta palavra, tendo como referência o seu corpus, foi em 1899. No entanto, nos documentos de registro de batizados consultados para este trabalho, percebe-se que a variante banguella já era usada bem antes desta data, uma vez que esses documentos eclesiásticos são de 1837 a 1838.

Cabra - Acredita-se que esta lexia se refere à cor da pele do negro escravo, neste caso, a olhar pelo contexto de uso desta lexia e pela definição dos referidos dicionários e vocabulário, entende-se cabra como o indivíduo mestiço de mulato (branco com negro) com preto. Portanto, essa lexia alude a características do indivíduo que justificavam a denominação cabra, baseando-se nos seus traços físicos e hereditários. 
Senhor - Constante em todas as obras consultadas com a ideia de posse de algo, nota-se que em Amaral (1976) e Moraes Silva (1922), a lexia senhor faz menção ao dono de escravos, o sentido mais adequado ao contexto dessa lexia, uma vez que está sendo usada para designar aquele que tem plenos poderes sobre o cativo, como pode ser observado neste trecho "Ellehe Senhor epos||58r|| Epossuidor dehum escravo crioulo denome Jus | tino, dei dade devinte annos mais ou | menos (fólio 57 verso e 58 recto)".

No entanto, ao analisar esta lexia em sua situação de uso é possível constatar que ser senhor é diferente de possuidor, uma vez que além de informar o senhorio de tal pessoa sobre o escravo ainda informa ser ele o seu possuidor, do que se infere que senhor designa apenas o proprietário do cativo, mas não significa que este se encontra em sua posse. Ressalta-se que, neste período escravocrata, era comum entre os senhores de escravos, hipotecar os negros escravos como garantia na tomada de um empréstimo, como se observa neste trecho "o qual elle desua livrevontade | Hypoteca, ehypotecado tem emmão epo | der de Pedro Martins Monteiro pela qu | antia de quatro centos etrinta mil | reis" (fólio 58 verso). Assim, enquanto a dívida não fosse quitada o escravo ficaria sob a posse do credor.

Após a análise das lexias e a observação das acepções nos instrumentos lexicográficos de natureza geral e regional, constata-se que não há uma variação linguística regional, uma vez que os sentidos registrados tanto por Amaral (1976) quanto por Ortêncio (2009), não diferiram dos que constam nos dicionários gerais da língua portuguesa.

Percebe-se, desta feita, como a língua é capaz de conservar e de reinventar delegando novos sentidos às lexias por meio da associação feita entre o nome e o referente, como no caso da unidade lexical banguela.

De início, tratava-se do nome de uma etnia africana, cuja marca registrada daqueles que dela faziam parte era ter os dentes incisivos menores porque eram serrados. Esse costume, no Brasil, foi associado à ausência de um ou mais dentes da arcada dentária. Daí por diante, aqueles que padeciam com a falta dos dentes passaram a ser denominados de banguelas. 


\section{Considerações finais}

Constatou-se, após o percurso teórico e analítico do estudo apresentado, que a língua, diassistema de caráter dinâmico e multifacetado, pode ser investigada na sua relação com a cultura, a partir de uma pesquisa interdisciplinar. Conquanto as duas ciências nas quais se estruturou a metodologia deste trabalho tenham a língua como foco de estudo, ambas investigam-na por matizes diferentes, como se demonstrou na análise empreendida.

A Lexicografia enseja registrar o léxico de língua de forma estruturada e organizada de acordo com a proposta lexicográfica que guia o tipo de produto lexicográfico que se deseja compor, atentando para as necessidades de elucidação dos usuários desses produtos.

De sua parte, a Filologia tem como material de análise o texto escrito com a finalidade de desvendar os percursos históricos pelas quais caminhou uma sociedade, seja em relação à evolução da própria língua quanto aos elementos linguísticos exteriores marcados na história de uma comunidade linguística, denotando os seus hábitos e costumes em tempos remotos.

Destaca-se, por fim, que as relações entre língua, cultura e história se mantêm vivas na memória dos agentes de uma sociedade graças ao léxico e a sua capacidade de traduzir, através dos signos linguísticos, todos os elementos do mundo que os cerca.

\section{Referências}

ABBADE, Celina Márcia de Souza. Um estudo lexical do primeiro manuscrito da culinária portuguesa medieval: o livro de cozinha da Infanta D. Maria. Salvador: Quarteto, 2009.

. A Lexicologia e a teoria dos campos lexicais. In: CONGRESSO

NACIONAL DE LINGUÍSTICA E FILOLOGIA, 15., 2011, Rio de Janeiro. Anais ... Rio de Janeiro: CiFEFiL, 2011. n.5, p. 1332-1343.

ANDRADE, Carlos Antônio de. Livro de Notas do 20. Tabelliaõ (1886). Cartório do $2^{\circ}$. Ofício - Tabelionato de Catalão. Catalão-GO, 2007. 
AMARAL, Amadeu. Vocabulário. In: . O Dialeto Caipira. 3. ed. São Paulo: HUCITEC, Secretaria da Cultura, Ciência e Tecnologia, 1976 [1920].

BIDERMAN, Maria Teresa Camargo. As Ciências do léxico. In: OLIVEIRA, Ana Maria Pinto Pires de; ISQUERDO, Aparecida. Negri. (Org.). As ciências do léxico: lexicologia, lexicografia, terminologia. 2. ed. Campo Grande-MS; EDUFMS, 2001. p. 13-22.

1984. . O Dicionário Padrão da Língua. Alfa. São Paulo, v. 28 (supl.), p. 27-43,

BORBA, Francisco da Silva. Montagem de dicionários de língua. In:

Organização de dicionários. uma introdução à lexicografia. São Paulo: Ed. UNESP, 2003. p. 301-333.

COELHO, Braz José. Dicionários - estrutura e tipologia. In: . Linguagem

- Lexicologia e Ensino de Português. Catalão: Modelo, 2008. p. 13-43.

HOUAISS, Antônio; VILLAR, Mauro. Dicionário Eletrônico Houaiss da Língua Portuguesa. Versão 1.0. Rio de Janeiro: Objetiva, 2009.

KRIEGER, Maria da Graça. Lexicografia: o léxico no dicionário. In: SEABRA, Maria Cândida Trindade Costa de. (Org.). O léxico em estudo. Belo Horizonte: Faculdade de Letras da UFMG, 2006. p. 158-171.

LARAIA, Roque de Barros. Cultura: um conceito antropológico. 14. ed. Rio de Janeiro: Jorge Zahar, 2001.

MEGALE, Heitor; TOLEdo NETO, Silvio Almeida. Por minha letra e sinal: Documentos do ouro do século XVIII. Cotia-SP: Ateliê, 2005. (Coleção Diacrhonica).

MORAES SILVA, Antonio. Diccionario da Língua Portugueza. Fac-símile da 2. ed. Rio de Janeiro, 1922 [1813].

ORTÊNCIO, Bariani. Dicionário do Brasil Central. 2. ed. Goiânia: Kelps, 2009.

PALACÍN, Luis; MORAES, Maria Augusta Santana. História de Goiás (17221972). 6. ed. Goiânia: Ed. UCG, 1989.

PARÓQUIA NOSSA SENHORA MÃE DE DEUS, com rubrica do presidente da câmara Paroquial Francisco Domingues Si/veira de Souza. Livro de assentos de Registros de Baptizados. 52 fólios. Villa do Catalão, $1^{\circ}$ de Setembro de 1837.

PAULA, Maria Helena de. Rastros de velhos falares - léxico e cultura no vernáculo catalano. 2007. 521f. Tese (Doutorado em Linguística e Língua 
Portuguesa) - Faculdade de Ciências e Letras, Universidade Estadual Paulista, Araraquara, 2007.

SPINA, Segismundo. Introdução à edótica. São Paulo: Cultrix; Ed. da Universidade de São Paulo, 1977.

VILELA, Mário. Estudos de Lexicologia do Português. Coimbra: Livraria Almedina, 1994.

XAVIER, Vanessa Regina Duarte. Lexicologia, Lexicografia e Filologia: intersecções e especificidades epistemológicas. In: SIMPÓSIO INTERNACIONAL DE LETRAS E LINGUÍSTICA, 2011, Uberlandia. Anais... Uberlândia: EDUFU, 2011. v. 2, n 2, p. 1-7. 